\title{
$\triangle$-convergence for mixed-type total asymptotically nonexpansive mappings in hyperbolic spaces
}

\section{Li-Li Wan*}

"Correspondence:

15882872311@163.com School of Science, Southwest

University of Science and Technology, Mianyang, Sichuan 621010, China

\begin{abstract}
In this paper, we prove some $\triangle$-convergence theorems in a hyperbolic space. A mixed Agarwal-O'Regan-Sahu type iterative scheme for approximating a common fixed point of total asymptotically nonexpansive mappings is constructed. Our results extend some results in the literature.

MSC: 47H09; 49M05

Keywords: total asymptotically nonexpansive mappings; hyperbolic space; $\triangle$-convergence; mixed Agarwal-O'Regan-Sahu type iterative scheme
\end{abstract}

\section{Introduction and preliminaries}

In this paper, we work in the setting of hyperbolic spaces introduced by Kohlenbach [1]. Concretely, $(X, d, W)$ is called a hyperbolic space if $(X, d)$ is a metric space and $W: X \times$ $X \times[0,1] \rightarrow X$ is a function satisfying

(I) $\forall x, y, z \in X, \forall \lambda \in[0,1], d(z, W(x, y, \lambda)) \leq(1-\lambda) d(z, x)+\lambda d(z, y)$;

(II) $\forall x, y \in X, \forall \lambda_{1}, \lambda_{2} \in[0,1], d\left(W\left(x, y, \lambda_{1}\right), W\left(x, y, \lambda_{2}\right)\right)=\left|\lambda_{1}-\lambda_{2}\right| \cdot d(x, y)$;

(III) $\forall x, y \in X, \forall \lambda \in[0,1], W(x, y, \lambda)=W(y, x,(1-\lambda))$;

(IV) $\forall x, y, z, w \in X, \forall \lambda \in[0,1], d(W(x, z, \lambda), W(y, w, \lambda)) \leq(1-\lambda) d(x, y)+\lambda d(z, w)$

If a space satisfies only (I), it coincides with the convex metric space introduced by Takahashi [2]. The concept of hyperbolic spaces in [1] is more restrictive than the hyperbolic type introduced by Goebel [3] since (I)-(III) together are equivalent to $(X, d, W)$ being a space of hyperbolic type in [3]. But it is slightly more general than the hyperbolic space defined in Reich [4] (see [1]). This class of metric spaces in [1] covers all normed linear spaces, $\mathbb{R}$-trees in the sense of Tits, the Hilbert ball with the hyperbolic metric (see [5]), Cartesian products of Hilbert balls, Hadamard manifolds (see $[4,6]$ ) and CAT(0) spaces in the sense of Gromov (see [7]). A thorough discussion of hyperbolic spaces and a detailed treatment of examples can be found in [1] (see also [3-5]).

A hyperbolic space is uniformly convex [8] if for $u, x, y \in X, r>0$ and $\epsilon \in(0,2]$, there exists $\delta \in(0,1]$ such that

$$
d\left(W\left(x, y, \frac{1}{2}\right), u\right) \leq(1-\delta) r
$$

provided that $d(x, u) \leq r, d(y, u) \leq r$ and $d(x, y) \geq \epsilon r$.

\section{Springer}

O2013 Wan; licensee Springer. This is an Open Access article distributed under the terms of the Creative Commons Attribution License (http://creativecommons.org/licenses/by/2.0), which permits unrestricted use, distribution, and reproduction in any medium, provided the original work is properly cited. 
A map $\eta:(0, \infty) \times(0,2] \rightarrow(0,1]$ is called modulus of uniform convexity if $\delta=\eta(r, \epsilon)$ for given $r>0$. Besides, $\eta$ is monotone if it decreases with $r$ (for a fixed $\epsilon$ ), that is,

$$
\eta\left(r_{2}, \epsilon\right) \leq \eta\left(r_{1}, \epsilon\right), \quad \forall r_{2} \geq r_{1}>0
$$

A subset $C$ of a hyperbolic space $X$ is convex if $W(x, y, \lambda) \in C$ for all $x, y \in C$ and $\lambda \in[0,1]$. Let $(X, d)$ be a metric space, and let $C$ be a nonempty subset of $X$. Recall that $T: C \rightarrow C$ is said to be a $\left(\left\{v_{n}\right\},\left\{\mu_{n}\right\}, \zeta\right)$-total asymptotically nonexpansive mapping if there exist nonnegative sequences $\left\{v_{n}\right\},\left\{\mu_{n}\right\}$ with $v_{n} \rightarrow 0, \mu_{n} \rightarrow 0$ and a strictly increasing continuous function $\zeta:[0, \infty) \rightarrow[0, \infty)$ with $\zeta(0)=0$ such that

$$
d\left(T^{n} x, T^{n} y\right) \leq d(x, y)+v_{n} \zeta(d(x, y))+\mu_{n}, \quad \forall n \geq 1, x, y \in C
$$

It is well known that each nonexpansive mapping is an asymptotically nonexpansive mapping and each asymptotically nonexpansive mapping is a $\left(\left\{v_{n}\right\},\left\{\mu_{n}\right\}, \zeta\right)$-total asymptotically nonexpansive mapping.

$T: C \rightarrow C$ is said to be uniformly L-Lipschitzian if there exists a constant $L>0$ such that

$$
d\left(T^{n} x, T^{n} y\right) \leq L d(x, y), \quad \forall n \geq 1, x, y \in C .
$$

The following iteration process is a translation of the mixed Agarwal-O'Regan-Sahu type iterative scheme introduced in [9] from Banach spaces to hyperbolic spaces. The iteration rate of convergence is similar to the Picard iteration process and faster than other fixed point iteration processes. Besides, it is independent of Mann and Ishikawa iteration processes.

$$
\left\{\begin{array}{l}
x_{1} \in C, \\
x_{n+1}=W\left(S_{1}^{n} x_{n}, T_{1}^{n} y_{n}, \alpha_{n}\right), \quad n \geq 1, \\
y_{n}=W\left(S_{2}^{n} x_{n}, T_{2}^{n} x_{n}, \beta_{n}\right),
\end{array}\right.
$$

where $C$ is a nonempty closed and convex subset of a complete uniformly convex hyperbolic space $X$ with monotone modulus of uniform convexity $\eta$. $T_{i}: C \rightarrow C, i=1$, 2 , is a uniformly $L_{i}$-Lipschitzian and $\left(\left\{v_{n}^{(i)}\right\},\left\{\mu_{n}^{(i)}\right\}, \zeta^{(i)}\right)$-total asymptotically nonexpansive mapping, and $S_{i}: C \rightarrow C, i=1,2$, is a uniformly $\widetilde{L}_{i}$-Lipschitzian and $\left(\left\{\widetilde{v}_{n}^{(i)}\right\},\left\{\widetilde{\mu}_{n}^{(i)}\right\}, \widetilde{\zeta}^{(i)}\right)$-total asymptotically nonexpansive mapping such that the following conditions are satisfied:

(1) $\sum_{n=1}^{\infty} v_{n}^{(i)}<\infty, \sum_{n=1}^{\infty} \mu_{n}^{(i)}<\infty, \sum_{n=1}^{\infty} \widetilde{v}_{n}^{(i)}<\infty, \sum_{n=1}^{\infty} \widetilde{\mu}_{n}^{(i)}<\infty, i=1,2$;

(2) There exists a constant $M>0$ such that $\zeta^{(i)}(r) \leq M r, \widetilde{\zeta}^{(i)}(r) \leq M r, \forall r \geq 0, i=1,2$.

Remark 1 Without loss of generality, we can assume that $T_{i}: C \rightarrow C$ and $S_{i}: C \rightarrow C, i=$ 1,2 , both are uniformly $L$-Lipschitzian and $\left(\left\{v_{n}\right\},\left\{\mu_{n}\right\}, \zeta\right)$-total asymptotically nonexpansive mappings satisfying conditions (1) and (2). In fact, letting $v_{n}=\max \left\{v_{n}^{(i)}, \widetilde{v}_{n}^{(i)}, i=1,2\right\}$, $\mu_{n}=\max \left\{\mu_{n}^{(i)}, \tilde{\mu}_{n}^{(i)}, i=1,2\right\}, L=\max \left\{L_{i}, \tilde{L}_{i}, i=1,2\right\}$ and $\zeta=\max \left\{\zeta^{(i)}, \widetilde{\zeta}^{(i)}, i=1,2\right\}$, then $S_{i}$ and $T_{i}, i=1,2$, are the required mappings.

Chang [10] proved some strong convergence theorems and $\triangle$-convergence theorems for approximating a common fixed point of total asymptotically nonexpansive mappings 
in a $\mathrm{CAT}(0)$ space using the mixed Agarwal-O'Regan-Sahu type iterative scheme. More precisely, one of the results is as follows.

Theorem 1 [10] Let $C$ be a bounded closed and convex subset of a complete CAT(0) space $X$. Let $T_{i}: C \rightarrow C$ and $S_{i}: C \rightarrow C, i=1,2$, be uniformly L-Lipschitzian and $\left(\left\{v_{n}\right\},\left\{\mu_{n}\right\}, \zeta\right)$-total asymptotically nonexpansive mappings. If $\mathcal{F}:=\bigcap_{i=1}^{2} F\left(T_{i}\right) \cap F\left(S_{i}\right) \neq \emptyset$ and the following conditions are satisfied:

(i) $\sum_{n=1}^{\infty} v_{n}<\infty$ and $\sum_{n=1}^{\infty} \mu_{n}<\infty$;

(ii) there exist constants $a, b \in(0,1)$ with $0<b(1-a) \leq \frac{1}{2}$ such that $\left\{\alpha_{n}\right\} \subset[a, b]$;

(iii) there exists a constant $M>0$ such that $\zeta(r) \leq M r, r \geq 0$;

(iv) $d\left(x, T_{i} y\right) \leq d\left(S_{i} x, T_{i} y\right)$ for all $x, y \in C$ and $i=1,2$,

then the sequence $\left\{x_{n}\right\}$ defined by (2) $\triangle$-converges to a common fixed point of $T_{i}$ and $S_{i}$, $i=1,2$.

Theorem 1 can be viewed as a improvement and extension of several well-known results in Banach spaces and CAT(0) spaces, such as [9] and [11]. Our purpose of this paper is to extend Theorem 1 from the $\mathrm{CAT}(0)$ spaces setting to the general setup of uniformly convex hyperbolic spaces.

Let $\left\{x_{n}\right\}$ be a bounded sequence in a hyperbolic space $X$. For $x \in X$, we define

$$
r\left(x,\left\{x_{n}\right\}\right)=\limsup _{n \rightarrow \infty} d\left(x, x_{n}\right)
$$

The asymptotic radius $r\left(\left\{x_{n}\right\}\right)$ of $\left\{x_{n}\right\}$ is given by

$$
r\left(\left\{x_{n}\right\}\right)=\inf \left\{r\left(x,\left\{x_{n}\right\}\right): x \in X\right\} .
$$

The asymptotic radius $r_{C}\left(\left\{x_{n}\right\}\right)$ of $\left\{x_{n}\right\}$ with respect to $C \subset X$ is given by

$$
r_{C}\left(\left\{x_{n}\right\}\right)=\inf \left\{r\left(x,\left\{x_{n}\right\}\right): x \in C\right\} .
$$

The asymptotic center $A\left(\left\{x_{n}\right\}\right)$ of $\left\{x_{n}\right\}$ is the set

$$
A\left(\left\{x_{n}\right\}\right)=\left\{x \in X: r\left(x,\left\{x_{n}\right\}\right)=r\left(\left\{x_{n}\right\}\right)\right\} .
$$

The asymptotic center $A_{C}\left(\left\{x_{n}\right\}\right)$ of $\left\{x_{n}\right\}$ with respect to $C \subset X$ is the set

$$
A_{C}\left(\left\{x_{n}\right\}\right)=\left\{x \in C: r\left(x,\left\{x_{n}\right\}\right)=r_{C}\left(\left\{x_{n}\right\}\right)\right\} .
$$

Recall that a sequence $\left\{x_{n}\right\}$ in $X$ is said to $\triangle$-converge to $x \in X$ if $x$ is the unique asymptotic center of $\left\{u_{n}\right\}$ for every subsequence $\left\{u_{n}\right\}$ of $\left\{x_{n}\right\}$. In this case, we call $x$ the $\triangle$-limit of $\left\{x_{n}\right\}$. The following lemmas are important in our paper.

Lemma $1[12,13]$ Let $(X, d, W)$ be a complete uniformly convex hyperbolic space with monotone modulus of uniform convexity, and let $C$ be a nonempty closed convex subset of $X$. Then every bounded sequence $\left\{x_{n}\right\}$ in $X$ has a unique asymptotic center with respect to $C$. 
Lemma 2 [12] Let $(X, d, W)$ be a uniformly convex hyperbolic space with monotone modulus of uniform convexity $\eta$. Let $x \in X$ and $\left\{\alpha_{n}\right\}$ be a sequence in $[a, b]$ for some $a, b \in(0,1)$. If $\left\{x_{n}\right\}$ and $\left\{y_{n}\right\}$ are sequences in $X$ such that $\limsup _{n \rightarrow \infty} d\left(x_{n}, x\right) \leq c, \limsup _{n \rightarrow \infty} d\left(y_{n}, x\right) \leq c$ and $\lim _{n \rightarrow \infty} d\left(W\left(x_{n}, y_{n}, \alpha_{n}\right), x\right)=c$ for some $c \geq 0$, then

$$
\lim _{n \rightarrow \infty} d\left(x_{n}, y_{n}\right)=0
$$

Lemma 3 [12] Let $C$ be a nonempty closed convex subset of a uniformly convex hyperbolic space, and let $\left\{x_{n}\right\}$ be a bounded sequence in C such that $A\left(\left\{x_{n}\right\}\right)=\{y\}$ and $r\left(\left\{x_{n}\right\}\right)=\rho$. If $\left\{y_{m}\right\}$ is another sequence in $C$ such that $\lim _{m \rightarrow \infty} r\left(y_{m},\left\{x_{n}\right\}\right)=\rho$, then $\lim _{m \rightarrow \infty} y_{m}=y$.

Lemma 4 [10] Let $\left\{a_{n}\right\},\left\{b_{n}\right\}$ and $\left\{c_{n}\right\}$ be sequences of nonnegative numbers such that

$$
a_{n+1} \leq\left(1+b_{n}\right) a_{n}+c_{n}, \quad \forall n \geq 1 .
$$

If $\sum_{n=1}^{\infty} b_{n}<\infty$ and $\sum_{n=1}^{\infty} c_{n}<\infty$, then $\lim _{n \rightarrow \infty} a_{n}$ exists.

\section{Main results}

In this section, we prove our main theorems.

Theorem 2 Let $C$ be a nonempty closed and convex subset of a complete uniformly convex hyperbolic space $X$ with monotone modulus of uniform convexity $\eta$. Let $T_{i}: C \rightarrow C$ and $S_{i}: C \rightarrow C, i=1,2$, be uniformly L-Lipschitzian and $\left(\left\{v_{n}\right\},\left\{\mu_{n}\right\}, \zeta\right)$-total asymptotically nonexpansive mappings. If $\mathcal{F}:=\bigcap_{i=1}^{2} F\left(T_{i}\right) \cap F\left(S_{i}\right) \neq \emptyset$ and the following conditions are satisfied:

(i) $\sum_{n=1}^{\infty} v_{n}<\infty$ and $\sum_{n=1}^{\infty} \mu_{n}<\infty$;

(ii) there exist constants $a, b \in(0,1)$ such that $\left\{\alpha_{n}\right\} \subset[a, b]$;

(iii) there exists a constant $M>0$ such that $\zeta(r) \leq M r, r \geq 0$;

(iv) $d\left(x, T_{i} y\right) \leq d\left(S_{i} x, T_{i} y\right)$ for all $x, y \in C$ and $i=1,2$,

then the sequence $\left\{x_{n}\right\}$ defined by (2) $\triangle$-converges to a common fixed point of $T_{i}$ and $S_{i}$, $i=1,2$.

Proof We divide our proof into three steps.

Step 1. In the sequel, we shall show that for each $p \in \mathcal{F}$,

$$
\lim _{n \rightarrow \infty} d\left(x_{n}, p\right) \text { and } \lim _{n \rightarrow \infty} d\left(x_{n}, \mathcal{F}\right) \text { exist. }
$$

In fact, by conditions (1), (2), (I) and (iii), one gets

$$
\begin{aligned}
d\left(y_{n}, p\right) & =d\left(W\left(S_{2}^{n} x_{n}, T_{2}^{n} x_{n}, \beta_{n}\right), p\right) \\
& \leq\left(1-\beta_{n}\right) d\left(S_{2}^{n} x_{n}, p\right)+\beta_{n} d\left(T_{2}^{n} x_{n}, p\right) \\
& \leq\left(1-\beta_{n}\right)\left\{d\left(x_{n}, p\right)+v_{n} \zeta\left(d\left(x_{n}, p\right)\right)+\mu_{n}\right\}+\beta_{n}\left\{d\left(x_{n}, p\right)+v_{n} \zeta\left(d\left(x_{n}, p\right)\right)+\mu_{n}\right\} \\
& =d\left(x_{n}, p\right)+v_{n} \zeta\left(d\left(x_{n}, p\right)\right)+\mu_{n} \\
& \leq\left(1+v_{n} M\right) d\left(x_{n}, p\right)+\mu_{n}
\end{aligned}
$$


and

$$
\begin{aligned}
d\left(x_{n+1}, p\right) & =d\left(W\left(S_{1}^{n} x_{n}, T_{1}^{n} y_{n}, \alpha_{n}\right), p\right) \\
& \leq\left(1-\alpha_{n}\right) d\left(S_{1}^{n} x_{n}, p\right)+\alpha_{n} d\left(T_{1}^{n} y_{n}, p\right) \\
& \leq\left(1-\alpha_{n}\right)\left\{d\left(x_{n}, p\right)+v_{n} \zeta\left(d\left(x_{n}, p\right)\right)+\mu_{n}\right\}+\alpha_{n}\left\{d\left(y_{n}, p\right)+v_{n} \zeta\left(d\left(y_{n}, p\right)\right)+\mu_{n}\right\} \\
& \leq\left(1-\alpha_{n}\right)\left\{\left(1+v_{n} M\right) d\left(x_{n}, p\right)+\mu_{n}\right\}+\alpha_{n}\left\{\left(1+v_{n} M\right) d\left(y_{n}, p\right)+\mu_{n}\right\}
\end{aligned}
$$

Combining (4) and (5), one has

$$
d\left(x_{n+1}, p\right) \leq\left(1+\sigma_{n}\right) d\left(x_{n}, p\right)+\xi_{n}, \quad \forall n \geq 1 \text { and } p \in \mathcal{F}
$$

and

$$
d\left(x_{n+1}, \mathcal{F}\right) \leq\left(1+\sigma_{n}\right) d\left(x_{n}, \mathcal{F}\right)+\xi_{n}, \quad \forall n \geq 1,
$$

where $\sigma_{n}=v_{n} M\left(1+\alpha_{n}\left(1+v_{n} M\right)\right), \xi_{n}=\left(1+\alpha_{n}\left(1+v_{n} M\right)\right) \mu_{n}$. Furthermore, using condition (i), one has

$$
\sum_{n=1}^{\infty} \sigma_{n}<\infty \text { and } \sum_{n=1}^{\infty} \xi_{n}<\infty
$$

Consequently, a combination of (6), (7), (8) and Lemma 4 shows that (3) is proved.

Step 2. We claim that

$$
\lim _{n \rightarrow \infty} d\left(x_{n}, T_{i} x_{n}\right)=0 \quad \text { and } \quad \lim _{n \rightarrow \infty} d\left(x_{n}, S_{i} x_{n}\right)=0, \quad i=1,2 .
$$

In fact, it follows from (3) that $\lim _{n \rightarrow \infty} d\left(x_{n}, p\right)$ exists for each given $p \in \mathcal{F}$. Without loss of generality, we assume that

$$
\lim _{n \rightarrow \infty} d\left(x_{n}, p\right)=c \geq 0
$$

By (4) and (10), one has

$$
\liminf _{n \rightarrow \infty} d\left(y_{n}, p\right) \leq \limsup _{n \rightarrow \infty} d\left(y_{n}, p\right) \leq \lim _{n \rightarrow \infty}\left\{\left(1+v_{n} M\right) d\left(x_{n}, p\right)+\mu_{n}\right\}=c
$$

Noting

$$
\begin{aligned}
d\left(T_{1}^{n} y_{n}, p\right) & =d\left(T_{1}^{n} y_{n}, T_{1}^{n} p\right) \\
& \leq d\left(y_{n}, p\right)+v_{n} \zeta\left(d\left(y_{n}, p\right)\right)+\mu_{n} \\
& \leq\left(1+v_{n} M\right) d\left(y_{n}, p\right)+\mu_{n}, \quad \forall n \geq 1,
\end{aligned}
$$

and

$$
\begin{aligned}
d\left(S_{1}^{n} x_{n}, p\right) & =d\left(S_{1}^{n} x_{n}, S_{1}^{n} p\right) \\
& \leq d\left(x_{n}, p\right)+v_{n} \zeta\left(d\left(x_{n}, p\right)\right)+\mu_{n} \\
& \leq\left(1+v_{n} M\right) d\left(x_{n}, p\right)+\mu_{n}, \quad \forall n \geq 1,
\end{aligned}
$$


by (10) and (11), one has

$$
\limsup _{n \rightarrow \infty} d\left(T_{1}^{n} y_{n}, p\right) \leq c \quad \text { and } \quad \limsup _{n \rightarrow \infty} d\left(S_{1}^{n} x_{n}, p\right) \leq c
$$

Besides, by (6) one gets

$$
d\left(x_{n+1}, p\right)=d\left(W\left(S_{1}^{n} x_{n}, T_{1}^{n} y_{n}, \alpha_{n}\right), p\right) \leq\left(1+\sigma_{n}\right) d\left(x_{n}, p\right)+\xi_{n},
$$

which yields that

$$
\lim _{n \rightarrow \infty} d\left(W\left(S_{1}^{n} x_{n}, T_{1}^{n} y_{n}, \alpha_{n}\right), p\right)=c .
$$

Now, by (12), (13) and Lemma 2, we have

$$
\lim _{n \rightarrow \infty} d\left(S_{1}^{n} x_{n}, T_{1}^{n} y_{n}\right)=0
$$

Using the same method, we can also have that

$$
\lim _{n \rightarrow \infty} d\left(S_{2}^{n} x_{n}, T_{2}^{n} x_{n}\right)=0
$$

It follows from (14), (15) and condition (iv) that

$$
\lim _{n \rightarrow \infty} d\left(x_{n}, T_{1}^{n} y_{n}\right) \leq \lim _{n \rightarrow \infty} d\left(S_{1}^{n} x_{n}, T_{1}^{n} y_{n}\right)=0
$$

and

$$
\lim _{n \rightarrow \infty} d\left(x_{n}, T_{2}^{n} x_{n}\right) \leq \lim _{n \rightarrow \infty} d\left(S_{2}^{n} x_{n}, T_{2}^{n} x_{n}\right)=0 .
$$

By virtue of (15), one has

$$
\begin{aligned}
d\left(y_{n}, S_{2}^{n} x_{n}\right) & =d\left(W\left(S_{2}^{n} x_{n}, T_{2}^{n} x_{n}, \beta_{n}\right), S_{2}^{n} x_{n}\right) \\
& \leq \beta_{n} d\left(T_{2}^{n} x_{n}, S_{2}^{n} x_{n}\right) \rightarrow 0 \quad \text { as } n \rightarrow \infty
\end{aligned}
$$

Because we have

$$
d\left(x_{n}, y_{n}\right) \leq d\left(x_{n}, T_{2}^{n} x_{n}\right)+d\left(T_{2}^{n} x_{n}, S_{2}^{n} x_{n}\right)+d\left(S_{2}^{n} x_{n}, y_{n}\right),
$$

it follows from (15), (17) and (18) that

$$
\lim _{n \rightarrow \infty} d\left(x_{n}, y_{n}\right)=0
$$

Combining (16) and (19), one obtains

$$
\begin{aligned}
d\left(x_{n}, T_{1}^{n} x_{n}\right) & \leq d\left(x_{n}, T_{1}^{n} y_{n}\right)+d\left(T_{1}^{n} y_{n}, T_{1}^{n} x_{n}\right) \\
& \leq d\left(x_{n}, T_{1}^{n} y_{n}\right)+d\left(x_{n}, y_{n}\right)+v_{n} \zeta\left(d\left(x_{n}, y_{n}\right)\right)+\mu_{n} \\
& \leq d\left(x_{n}, T_{1}^{n} y_{n}\right)+\left(1+v_{n} M\right) d\left(x_{n}, y_{n}\right)+\mu_{n} \rightarrow 0 \quad \text { as } n \rightarrow \infty .
\end{aligned}
$$


Moreover, it follows from (16) and (19) that

$$
\begin{aligned}
d\left(S_{1}^{n} x_{n}, T_{1}^{n} x_{n}\right) & \leq d\left(S_{1}^{n} x_{n}, T_{1}^{n} y_{n}\right)+d\left(T_{1}^{n} y_{n}, T_{1}^{n} x_{n}\right) \\
& \leq d\left(S_{1}^{n} x_{n}, T_{1}^{n} y_{n}\right)+L d\left(y_{n}, x_{n}\right) \rightarrow 0 \quad \text { as } n \rightarrow \infty
\end{aligned}
$$

This jointly with (16) and (20) yields that

$$
d\left(S_{1}^{n} x_{n}, x_{n}\right) \leq d\left(S_{1}^{n} x_{n}, T_{1}^{n} x_{n}\right)+d\left(T_{1}^{n} x_{n}, x_{n}\right) \rightarrow 0 \quad \text { as } n \rightarrow \infty
$$

and

$$
\begin{aligned}
d\left(x_{n+1}, x_{n}\right) & \leq d\left(W\left(S_{1}^{n} x_{n}, T_{1}^{n} y_{n}, \alpha_{n}\right), x_{n}\right) \\
& \leq\left(1-\alpha_{n}\right) d\left(S_{1}^{n} x_{n}, x_{n}\right)+\alpha_{n} d\left(T_{1}^{n} y_{n}, x_{n}\right) \rightarrow 0 \quad \text { as } n \rightarrow \infty
\end{aligned}
$$

Now by (17), (20) and (22), for each $i=1,2$, one gets

$$
\begin{aligned}
d\left(x_{n}, T_{i} x_{n}\right) \leq & d\left(x_{n}, x_{n+1}\right)+d\left(x_{n+1}, T_{i}^{n+1} x_{n+1}\right)+d\left(T_{i}^{n+1} x_{n+1}, T_{i}^{n+1} x_{n}\right) \\
& +d\left(T_{i}^{n+1} x_{n}, T_{i} x_{n}\right) \\
\leq & (1+L) d\left(x_{n}, x_{n+1}\right)+d\left(x_{n+1}, T_{i}^{n+1} x_{n+1}\right) \\
& +L d\left(T_{i}^{n} x_{n}, x_{n}\right) \rightarrow 0 \quad \text { as } n \rightarrow \infty .
\end{aligned}
$$

For each $i=1,2$, the combination of (15), (17), (20), (21) and (iv) yields that

$$
\begin{aligned}
d\left(x_{n}, S_{i} x_{n}\right) & \leq d\left(x_{n}, T_{i}^{n} x_{n}\right)+d\left(S_{i} x_{n}, T_{i}^{n} x_{n}\right) \\
& \leq d\left(x_{n}, T_{i}^{n} x_{n}\right)+d\left(S_{i}^{n} x_{n}, T_{i}^{n} x_{n}\right) \rightarrow 0 \quad \text { as } n \rightarrow \infty .
\end{aligned}
$$

Therefore, (9) is proved.

Step 3. Now we are in a position to prove the $\triangle$-convergence of $\left\{x_{n}\right\}$. Since $\left\{x_{n}\right\}$ is bounded, by Lemma 1, it has a unique asymptotic center $A_{C}\left(\left\{x_{n}\right\}\right)=\left\{x^{*}\right\}$. Let $\left\{u_{n}\right\}$ be any subsequence of $\left\{x_{n}\right\}$ with $A_{C}\left(\left\{u_{n}\right\}\right)=\{u\}$, then by (23) and (24), for each $i=1,2$, we have

$$
\lim _{n \rightarrow \infty} d\left(u_{n}, T_{i} u_{n}\right)=0 \text { and } d\left(u_{n}, S_{i} u_{n}\right)=0
$$

We claim that $u \in \mathcal{F}$. In fact, we define a sequence $\left\{z_{m}\right\}$ in $C$ by $z_{m}=T_{1}^{m} u$. Then one has

$$
\begin{aligned}
d\left(z_{m}, u_{n}\right) & \leq d\left(T_{1}^{m} u, T_{1}^{m} u_{n}\right)+d\left(T_{1}^{m} u_{n}, T_{1}^{m-1} u_{n}\right)+\cdots+d\left(T_{1} u_{n}, u_{n}\right) \\
& \leq d\left(u, u_{n}\right)+v_{n} \zeta\left(d\left(u, u_{n}\right)\right)+\mu_{n}+\operatorname{Ld}\left(T_{1} u_{n}, u_{n}\right)+\cdots+d\left(T_{1} u_{n}, u_{n}\right) .
\end{aligned}
$$

By (25), one gets

$$
\limsup _{n \rightarrow \infty} d\left(z_{m}, u_{n}\right) \leq \limsup _{n \rightarrow \infty} d\left(u, u_{n}\right)=r\left(u,\left\{u_{n}\right\}\right),
$$

which yields that

$$
\left|r\left(z_{m},\left\{u_{n}\right\}\right)-r\left(u,\left\{u_{n}\right\}\right)\right| \rightarrow 0 \quad \text { as } m \rightarrow \infty .
$$


Lemma 3 shows that $\lim _{m \rightarrow \infty} T_{1}^{m} u=u$. Because $T_{1}$ is uniformly continuous, we have

$$
T_{1} u=T_{1}\left(\lim _{m \rightarrow \infty} T_{1}^{m} u\right)=\lim _{m \rightarrow \infty} T_{1}^{m+1} u=u .
$$

Hence, $u \in F\left(T_{1}\right)$. Using the same method, we can prove that $u \in \mathcal{F}$. By the uniqueness of asymptotic centers, we get that $x^{*}=u$. It implies that $x^{*}$ is the unique asymptotic center of $\left\{u_{n}\right\}$ for each subsequence $\left\{u_{n}\right\}$ of $\left\{x_{n}\right\}$, that is, $\left\{x_{n}\right\} \triangle$-converges to $x^{*} \in \mathcal{F}$. The proof is completed.

\section{Competing interests}

The author declares that they have no competing interests.

\section{Acknowledgements}

Supported by General Project of Educational Department in Sichuan (No. 13ZB0182) and Doctor Research Foundation of Southwest University of Science and Technology (No. 11zx7130).

Received: 30 August 2013 Accepted: 22 October 2013 Published: 22 Nov 2013

References

1. Kohlenbach, U: Some logical metatheorems with applications in functional analysis. Trans. Am. Math. Soc. 357, 89-128 (2005)

2. Takahashi, W: A convexity in metric spaces and nonexpansive mappings. Kodai Math. Semin. Rep. 22, 142-149 (1970)

3. Goebel, K, Kirk, WA: Iteration processes for nonexpansive mappings. In: Singh, SP, Thomeier, S, Watson, B (eds.) Topological Methods in Nonlinear Functional Analysis. Contemporary Mathematics vol. 21, pp. 115-123 Am. Math. Soc., Providence (1983)

4. Reich, S, Shafrir, I: Nonexpansive iterations in hyperbolic spaces. Nonlinear Anal., Theory Methods Appl. 15, 537-558 (1990)

5. Goebel, K, Reich, S: Uniform Convexity, Hyperbolic Geometry, and Nonexpansive Mappings. Monographs and Textbooks in Pure and Applied Mathematics, vol. 83, ix+170. Dekker, New York (1984)

6. Reich, S, Zaslavski, AJ: Generic aspects of metric fixed point theory. In: Kirk, WA, Sims, B (eds.) Handbook of Metric Fixed Point Theory, pp. 557-576. Kluwer Academic, Dordrecht (2001)

7. Bridson, M, Haefliger, A: Metric Spaces of Non-Positive Curvature. Springer, Berlin (1999)

8. Shimizu, T, Takahashi, W: Fixed points of multivalued mappings in certain convex metric spaces. Topol. Methods Nonlinear Anal. 8, 197-203 (1996)

9. Agarwal, RP, O'Regan, D, Sahu, DR: Iterative construction of fixed points of nearly asymptotically nonexpansive mappings. J. Nonlinear Convex Anal. 8, 61-79 (2007)

10. Chang, SS, Wang, L, Lee, HWJ, Chan, C: Strong and $\triangle$-convergence for mixed type total asymptotically nonexpansive mappings in CAT(0) spaces. Fixed Point Theory Appl. 2013, Article ID 122 (2013)

11. Sahin, A, Basarir, M: On the strong convergence of modified S-iteration process for asymptotically quasi-nonexpansive mappings in CAT(0) space. Fixed Point Theory Appl. 2013, Article ID 12 (2013)

12. Khan, AR, Fukhar-ud-din, H, Khan, MAA: An implicit algorithm for two finite families of nonexpansive maps in hyperbolic spaces. Fixed Point Theory Appl. 2012, Article ID 54 (2012)

13. Leustean, L: Nonexpansive iterations in uniformly convex W-hyperbolic spaces. In: Leizarowitz, A, Mordukhovich, BS, Shafrir, I, Zaslavski, A (eds.) Nonlinear Analysis and Optimization I: Nonlinear Analysis. Contemporary Mathematics, vol. 513, pp. 193-209. Am. Math. Soc., Providence (2010) 